\title{
Characteristics and Preparation of Designed Alginate-Based Composite Scaffold Membranes with Decellularized Fibrous Micro-Scaffold Structures from Porcine Skin
}

\author{
Ching-Cheng Huang 1,2 \\ 1 Department of Biomedical Engineering, Ming-Chuan University, Gui Shan District, Taoyuan 320-33, Taiwan; \\ junas.tw@yahoo.com.tw \\ 2 PARSD Biomedical Material Research Center, Xitun District, Taichung 407-49, Taiwan
}

check for

updates

Citation: Huang, C.-C.

Characteristics and Preparation of

Designed Alginate-Based Composite

Scaffold Membranes with

Decellularized Fibrous Micro-Scaffold

Structures from Porcine Skin.

Polymers 2021, 13, 3464. https://

doi.org/10.3390/polym13203464

Academic Editors: Ilaria Armentano and Alberto Figoli

Received: 21 July 2021

Accepted: 5 October 2021

Published: 9 October 2021

Publisher's Note: MDPI stays neutral with regard to jurisdictional claims in published maps and institutional affiliations.

Copyright: (C) 2021 by the author. Licensee MDPI, Basel, Switzerland. This article is an open access article distributed under the terms and conditions of the Creative Commons Attribution (CC BY) license (https:// creativecommons.org/licenses/by/ $4.0 /)$.

\begin{abstract}
Alginate-based composite scaffold membranes with various ratios of decellularized extracellular matrices could be designed and obtained from porcine skin tissue by using supercritical carbon dioxide fluid technology. Retention of decellularized extracellular matrix (dECM) and scaffold-structure integrity was observed. This work provides a simple and time-saving process for the preparation of biomedical alginate-based composite scaffold membranes with fibrous dECM micro-scaffolds, which were further characterized by Fourier transform infrared spectroscopy (FTIR), thermo-gravimetric analysis (TGA), and scanning electron microscope (SEM). The introduction of fibrous dECM micro-scaffolds enhanced the thermal stability and provided expected effects on the biological properties of the designed composite scaffold membranes in regenerative applications.
\end{abstract}

Keywords: supercritical carbon dioxide; microstructure; decellularization; alginate; composite scaffold membranes

\section{Introduction}

Numerous synthetic materials and natural materials have been proposed, modified, and employed for medical applications, such as 3D bioprinting scaffolds for skin and bone tissue reconstruction [1-16]. Three-dimensional (3D) bioprinting shows potential in tissue engineering and regenerative applications due to its overwhelming advantages over other approaches. In order to promote the functions of bioprinted tissues, the development of novel and versatile bioinks will have crucial implications [1]. Natural materials including agarose, alginate, gellan gum, dextran, hyaluronic acid (HA), silk, fibrin, collagen, decellularized extracellular matrix(dECM), cellulose, gelatin, and chitosan are famous for their excellent biocompatibility and abundance, among which sodium alginate mixed with gelatin has been widely used as a bioink for extrusion-based 3D bioprinting [2]. Despite advances in bioprinting and bio-fabrication during the past decade, fabricating complex and functional tissue constructs that mimic their natural counterparts remains a challenge [3].

Sodium alginate is a naturally occurring biopolymer extracted from different species of marine brown algae [12-17]. Sodium alginate, a marine-derived polysaccharide, can offer many advantages over synthetic polymers since they interact under relatively mild temperatures and $\mathrm{pH}$ levels [12-17]. Alginate shows a wide range of biomedical applications, especially in cell immobilization and tissue regeneration for 3D bioprinting applications, because of its outstanding properties, such as biodegradability and biocompatibility [14]. Alginate has attractive features, including ease of gelation with divalent cations such as calcium ions for enhanced stability of Ca-alginate [12-17].

Decellularized extracellular matrix (dECM) scaffolds have abundant levels of collagen, which constitutes the main structural element of the $\mathrm{dECM}$, provides tensile strength, regulates cell adhesion, supports migration, and directs tissue development. Dense connective tissue is an abundant source of dECM scaffolds, which can be prepared and purified by a defatting and decellularizing procedure $[4,6,11]$. 
The objectives of the present manuscript are to provide a new design of alginate-based composite scaffold membranes containing micro-scaffolds instead of macroscopic scaffolds and to provide expected effects on the biological properties of the scaffolds in regenerative applications [18-20]. Therefore, the designed dECM was prepared by using supercritical carbon dioxide and specific enzymes and were introduced in the composite scaffold membranes to provide a microstructure of micro-scaffolds [4]. The micro-scaffolds could be prepared efficiently by using supercritical fluid treatments instead of macroscopic bioprinting processes. The composite scaffold membranes containing collagen micro-scaffolds must be characterized by Fourier transform infrared spectroscopy (FTIR), thermo-gravimetric analysis (TGA), and scanning electron microscope (SEM) to get the results of identifications, thermal stabilities, and microstructures. A simple method for the evaluation of designed alginate-based composite scaffold membranes with decellularized scaffolds was built up through TGA results (DTG curves) that could easily identify the molecular interactions between alginate, calcium, and the AECM in the resulting composite scaffold membranes. The molecular interactions affected the thermal stability and physicochemical properties of macroscopic scaffolds. Furthermore, the introduction of micro-scaffolds into the composite scaffold membranes will be important for 3D bioprinting or regenerative applications.

\section{Materials and Methods}

\subsection{Materials}

The chemicals used in this work include the enzyme papain (Sigma-Aldrich Company, St. Louis, MO, USA), sodium alginate (Sigma-Aldrich Company), calcium chloride (Fluka Chemie GmbH, Buchs, Switzerland), Triton X-100 (t-octylphenoxypolyethoxyethanol) (Sigma-Aldrich Company), and $\mathrm{NaOH}$ (Sigma-Aldrich Company).

\subsection{Preparation of a Decellularized Extracellular Matrix Scaffold}

The supercritical fluid of carbon dioxide $\left(\mathrm{ScCO}_{2}\right)$ was employed for the preparation of newly designed decellularized extracellular matrix scaffolds in this study. The $\mathrm{ScCO}_{2}$ was employed before the enzyme treatments to remove most fatty acids and tissues [4]. The skin was placed in a tissue holder that was then placed into a $\mathrm{ScCO}_{2}$ vessel system. The $\mathrm{ScCO}_{2}$ system was then operated at 350 bar and $35^{\circ} \mathrm{C}$ for $2 \mathrm{~h}$.

The steady thickness of about $0.5 \mathrm{~mm}$ of thinly sliced tissue samples was obtained from the porcine dermal layer by using a designed tissue-cutting machine (Taiwan PARSD Pharm. Tech. Consulting Ltd., Co., Taichung, Taiwan) and Kuin Biotech. Ltd., Co., Xinbei, Taiwan). Residual fat tissues were cleaned from the skin, and the skin was washed with phosphatebuffered saline (PBS). The $\mathrm{ScCO}_{2}$ extraction was performed for complete decellularization. Samples were soaked in $25 \% \mathrm{NaOH}_{(\mathrm{aq})}$ for $2 \mathrm{~h}$ with a magnet mixer and then washed in $0.5 \mathrm{U} / \mathrm{mL}$ papain(aq) at $25{ }^{\circ} \mathrm{C}$ for $2 \mathrm{~h} \mathrm{[6]}$. The resulting samples were washed with double-distilled water under ultrasonic waves to remove residual fat and organic matter. The resulting sample was frozen for $6 \mathrm{~h}$ and then lyophilized (EYELA, FD-5N) overnight with the use of a freeze dryer at $0.1-0.2$ torr at a freeze-drying temperature of $-45^{\circ} \mathrm{C}$. A designed decellularized extracellular matrix scaffold, $\mathrm{dECM}$, was then be obtained.

\subsection{Preparation of Decellularized Extracellular Matrix/Alginate Composite Scaffold Membranes}

In this study, composite scaffold membranes with dECM scaffolds were prepared based on the various weight ratios of alginate and AECM (alginate/dECM: 100/0, 95/5, $90 / 10,85 / 15,80 / 20$ ). Briefly, the desired amount of dECM powder was first dispersed completely in $40 \mathrm{~mL}$ of double-distilled water with a homogenizer at 26,000 rpm(revolutions per minute) for $3 \mathrm{~min}$. Then, an alginate aqueous solution was homogenized thoroughly with the dispersed dECM solution at 26,000 rpm for $3 \mathrm{~min}$. The alginate/dECM solutions were molded and frozen for $6 \mathrm{~h}$ and then lyophilized (EYELA, FD-5N) overnight. New alginate/dECM composite scaffold membranes were obtained, such as AdE1N, AdE2N, AdE3N, and AdE4N (Table 1). 
Table 1. Preparation of new ALG/dECM composite scaffold membranes.

\begin{tabular}{ccc}
\hline Sample No. & ALG/dECM $^{\mathbf{a}}(\boldsymbol{w} / \boldsymbol{w})$ & $\mathbf{C a C l}_{\mathbf{2}}$ \\
\hline AdE0N $^{\mathrm{a}}$ & $100 / 0$ & - \\
AdE1N $^{\mathrm{a}}$ & $95 / 5$ & - \\
AdE2N $^{\mathrm{a}}$ & $90 / 10$ & - \\
AdE3N $^{\mathrm{a}}$ & $85 / 15$ & - \\
AdE4N $^{\mathrm{a}}$ & $80 / 20$ & - \\
AdE0L $^{\mathrm{a}, \mathrm{b}}$ & $100 / 0$ & $1 \mathrm{wt} \%$ \\
AdE1L $^{\mathrm{a}, \mathrm{b}}$ & $95 / 5$ & $1 \mathrm{wt} \%$ \\
AdE2L $^{\mathrm{a}, \mathrm{b}}$ & $90 / 10$ & $1 \mathrm{wt} \%$ \\
AdE3L $^{\mathrm{a}, \mathrm{b}}$ & $85 / 15$ & $1 \mathrm{wt} \%$ \\
AdE4L $^{\mathrm{a}, \mathrm{b}}$ & $80 / 20$ & $1 \mathrm{wt} \%$ \\
AdE0H $^{\mathrm{a}, \mathrm{c}}$ & $100 / 0$ & $5 \mathrm{wt} \%$ \\
AdE1H $^{\mathrm{a}, \mathrm{c}}$ & $95 / 5$ & $5 \mathrm{wt} \%$ \\
AdE2H $^{\mathrm{a}, \mathrm{c}}$ & $90 / 10$ & $5 \mathrm{wt} \%$ \\
AdE3H $^{\mathrm{a}, \mathrm{c}}$ & $85 / 15$ & $5 \mathrm{wt} \%$ \\
AdE4H $^{\mathrm{a}, \mathrm{c}}$ & $80 / 20$ & $5 \mathrm{wt} \%$ \\
\hline
\end{tabular}

a ALG(A): alginate and dECM(dE): porcine skins via $\mathrm{ScCO}_{2}$ and papain treatments.; ${ }^{\mathrm{b}}$ Relatively low concentration of $\left.\mathrm{CaCl}_{2(\mathrm{aq})}\right)^{\mathrm{c}}$ Relatively high concentration of $\mathrm{CaCl}_{2(\mathrm{aq})}$.

\subsection{Preparation of Cross-Linked Decellularized Extracellular Matrix/Alginate Composite Scaffold Membranes}

The decellularized extracellular matrix/alginate composite scaffold membranes were soaked in $\mathrm{CaCl}_{2}$ aqueous solutions with various concentrations for different cross-linking reactions with a magnet mixer. The cross-linked decellularized extracellular matrix/alginate composite scaffold membranes were then molded, frozen, and dried by the same procedure described above. Designed decellularized extracellular matrix/alginate composite scaffold membranes were obtained (Table 1).

\subsection{Measurements}

Fourier Transform Infrared (FTIR) spectra were recorded with a spectrometer (Nicolet IS10, Thermo Fisher Scientific, USA) using KBr discs and collecting data from $400-4000 \mathrm{~cm}^{-1}$. Thermal analysis was performed by Thermogravimetry Analysis (TGA) using a thermoanalyzer (7300TG/DTA, Seiko, Japan). All measurements employed a linear heating rate of $10^{\circ} \mathrm{C} \cdot \mathrm{min}^{-1}$, with nitrogen as carrier gas and a platinum empty pan as a reference material. Diameters of micro-scaffolds were studied by scanning electron microscopy (SEM) (S3400N, Hitachi, Japan).

\section{Results}

\subsection{Fourier Transform Infrared Spectroscopy Analysis of Alginate/dECM Composite} Scaffold Membranes

From the FTIR analysis of the original porcine skin (Figure 1A), absorption bands at $1452,1400,1337,1240,1203$, and $1080 \mathrm{~cm}^{-1}$ were attributed to amide III, containing $\delta\left(\mathrm{CH}_{2}\right)$, $\delta\left(\mathrm{CH}_{3}\right), v(\mathrm{C}-\mathrm{N})$, and $\delta(\mathrm{N}-\mathrm{H})$ absorptions of collagen in the original porcine skin. Amide I and amide II absorptions were found at 1632 and $1551 \mathrm{~cm}^{-1}$, respectively. The absorption band at $3301 \mathrm{~cm}^{-1} \delta(\mathrm{C}-\mathrm{H})$ was attributed to the fatty acid of the original porcine skin. The absorption band at $1744 \mathrm{~cm}^{-1} \delta(\mathrm{C}=\mathrm{O})$ was attributed to the fatty acid. The absorption bands of fatty acids were not observed in Figure 1B, which demonstrates the effectiveness of the supercritical carbon dioxide treatment.

Figure $1 \mathrm{C}$ shows the typical absorption bands of sodium alginate, mainly the $\mathrm{O}-\mathrm{H}$ stretching at $3424 \mathrm{~cm}^{-1}$, pyranoid ring (six-membered ring) $\mathrm{C}-\mathrm{H}$ stretching at 2903 and $2932 \mathrm{~cm}^{-1}$, COO asymmetric stretching at $1595 \mathrm{~cm}^{-1}$, COO symmetric stretching at $1408 \mathrm{~cm}^{-1}, \mathrm{C}-\mathrm{O}$ stretching at 1338 and $1298 \mathrm{~cm}^{-1}$, and C-O-C stretching at $1094 \mathrm{~cm}^{-1}$. Figure 1D still shows a remarkable absorption band at $2903 \mathrm{~cm}^{-1}$ on the spectra of ALG/dECM membranes, which indicates that the formation of the egg-box model due to 
cross-linking with calcium ions did not occur. If the formation of the egg-box model had occurred, the stretching vibration of $\mathrm{C}-\mathrm{H}$ in the six-membered ring of the calcium alginate molecule would be limited, and the corresponding absorption band could not be observed on the spectrum. In the sodium alginate molecule, the stretching vibration absorption band of $-\mathrm{COO}-$ and $\mathrm{C}-\mathrm{O}$ is very weak. However, in the calcium alginate molecule, the $-\mathrm{C}-\mathrm{O}-\mathrm{O}-\mathrm{Ca}-\mathrm{O}-\mathrm{CO}-$ structure makes the $\mathrm{C}-\mathrm{O}$ stretching vibration absorption increase and creates an obvious absorption band at $1024 \mathrm{~cm}^{-1}$, as shown in Figure 1C,D, which indicates the formation of the $-\mathrm{CO}-\mathrm{O}-\mathrm{Ca}-\mathrm{O}-\mathrm{CO}-$ structure in ALG/dECM membranes.

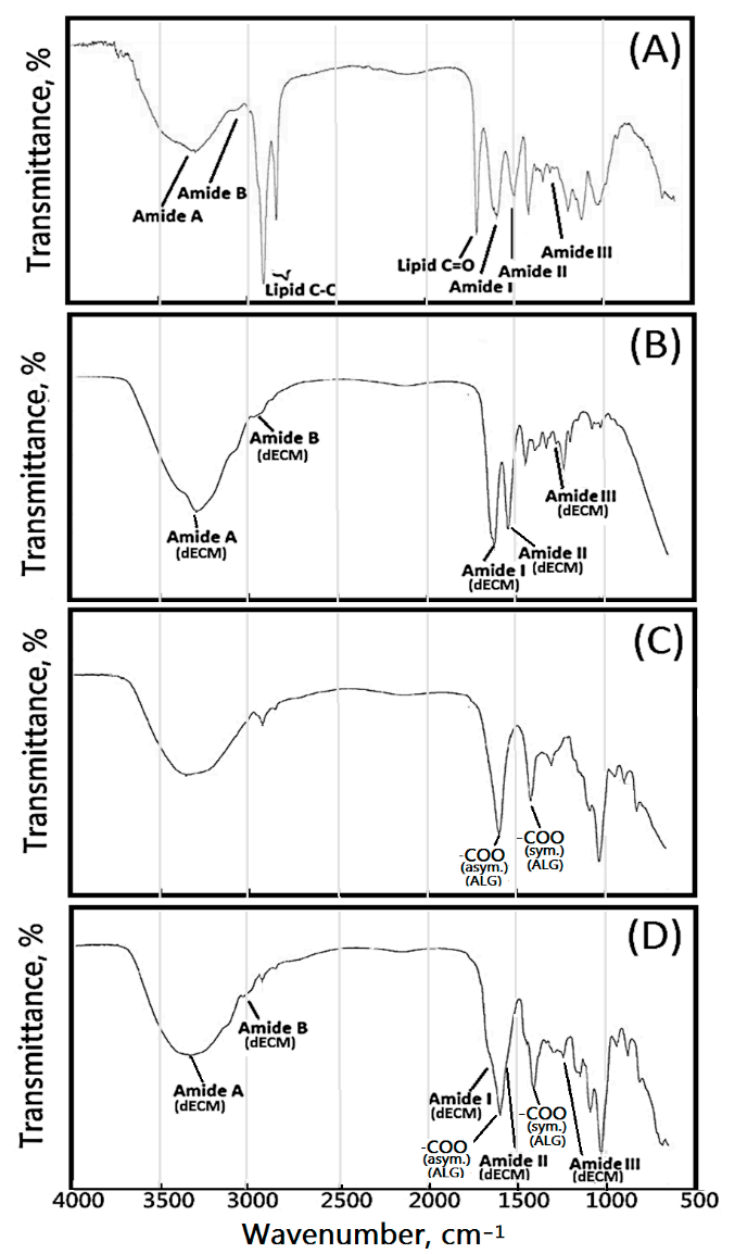

Figure 1. FTIR spectrum of the samples: (A) original porcine skin, (B) dECM, (C) AdE0N, and (D) cross-linked ALG/dECM composite scaffold membrane (AdE4H).

The FTIR spectroscopy analysis was carried out to confirm the incorporation of dECM in ALG/dECM composite scaffold membranes. The spectrum of the ALG/dECM composite scaffold membrane $(\mathrm{AdE} 4 \mathrm{H})($ Figure 1D), besides retaining the above-mentioned bands of pure sodium alginate (AdE0N) (Figure 1C), showed a stronger absorption band at $1595 \mathrm{~cm}^{-1}$ (the carbonyl $(\mathrm{C}=\mathrm{O})$ bond) and two remarkable shoulders at $1632 \mathrm{~cm}^{-1}$ and $1537 \mathrm{~cm}^{-1}$, which were characteristic absorption bands of carbonyl groups of amide and $\mathrm{dECM}$ molecules, which confirmed the formation of ALG/dECM composite scaffold membrane effectively. For the ALG/dECM composite scaffold membrane, the main absorption bands were also observed at around $1632 \mathrm{~cm}^{-1}$ (amide I, C-O, and C-N stretching), $1537 \mathrm{~cm}^{-1}$ (amide II), and $1242 \mathrm{~cm}^{-1}$ (amide III). There was higher absorption from $3600 \mathrm{~cm}^{-1}$ to $3200 \mathrm{~cm}^{-1}$ that appeared on the spectrum of the ALG/dECM scaffolds. This suggests an increase in hydrogen bonds resulting from the interaction between the $\mathrm{dECM}$ molecule and alginate (ALG) molecule. The results of FTIR indicate the presence of dECM in the hybrid scaffold as wells as the interaction between them. 


\subsection{The Microstructure of Resulting Alginate/dECM Composite Scaffold Membranes}

The microstructures of resulting membranes with dECM scaffolds were characterized by a scanning electron microscope (SEM). Scanning electron micrographs of original porcine skin, pretreated porcine skin by supercritical carbon dioxide, and IECM after treatment with supercritical carbon dioxide were showed in Figure 2A-C, respectively. Most of the residual fat tissues were removed to obtain a micro-scaffold structure. After the entire decellularization procedure, the clear micro-scaffold with a fibrous structure was observed directly in the AECM sample derived from porcine skin in the micrometer scale (Figure 2C). The diameter of the fibrous structure was found to range from 8 to $25 \mu \mathrm{m}$ (Figure 2C). The different micro-scaffolds shape relatively narrow boundaries while sheet structures of ALG samples were observed in SEM, as shown in Figure 2D. The diameter of the narrow boundaries was found to range from 1 to $3 \mu \mathrm{m}$. Macroscopic images of the composite scaffold membranes AdE4N and AdE4L were obtained in Figure 3. The micro-scaffold structures of the resulting alginate/dECM composite scaffold membranes were observed clearly whether the cross-linking reaction of $\mathrm{CaCl}_{2}$ was carried out or not. Furthermore, scanning electron micrographs of resulting new decellularized composite scaffold membranes are shown in Figure 4A-D. The remarkable micro-scaffolds with fibrous structures were observed in the composite scaffold membranes with various ratios of AECM and ALG. The merged structures of AdE1H and AdE2H with low dECM/ALG ratios were observed in Figure 4A,B. The merged structures combined the sheet structure of ALG molecules with the fibrous structure of $\mathrm{AECM}$ molecules. With the increasing introduction ratio of $\mathrm{dECM}$ to ALG, the new combined micro-scaffold shapes were observed with smooth fibrous structures, as shown in Figure 4C,D. The diameter of the smooth fibrous structures was found to range from 5 to $30 \mu \mathrm{m}$, which was similar to the micro-scaffold shape of dECM (Figure 2C).
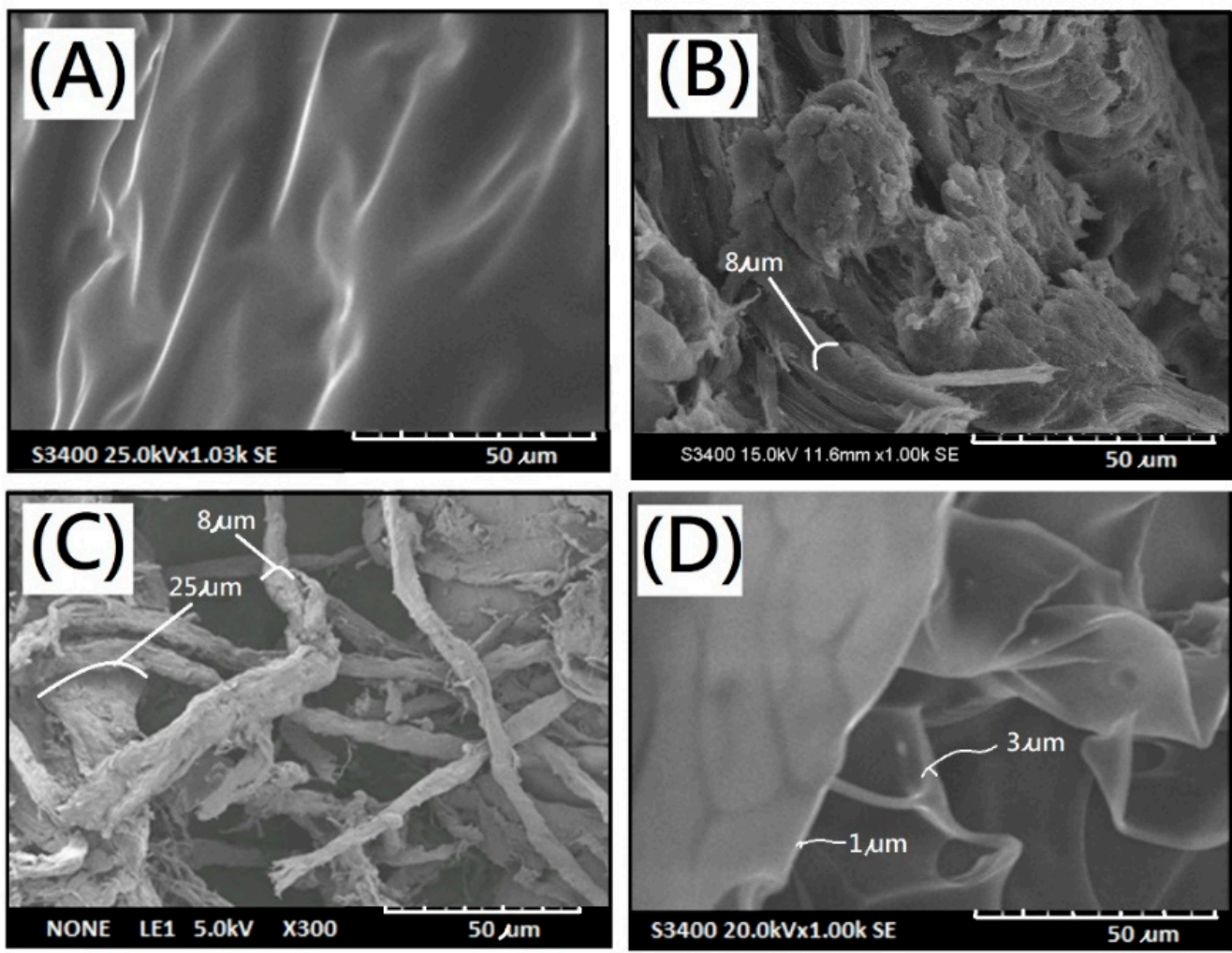

Figure 2. Scanning electron micrographs of samples of (A) original porcine skin, (B) pretreated porcine skin by $\mathrm{ScCO}_{2}$, (C) dECM powder, and (D) AdE0N membrane. 

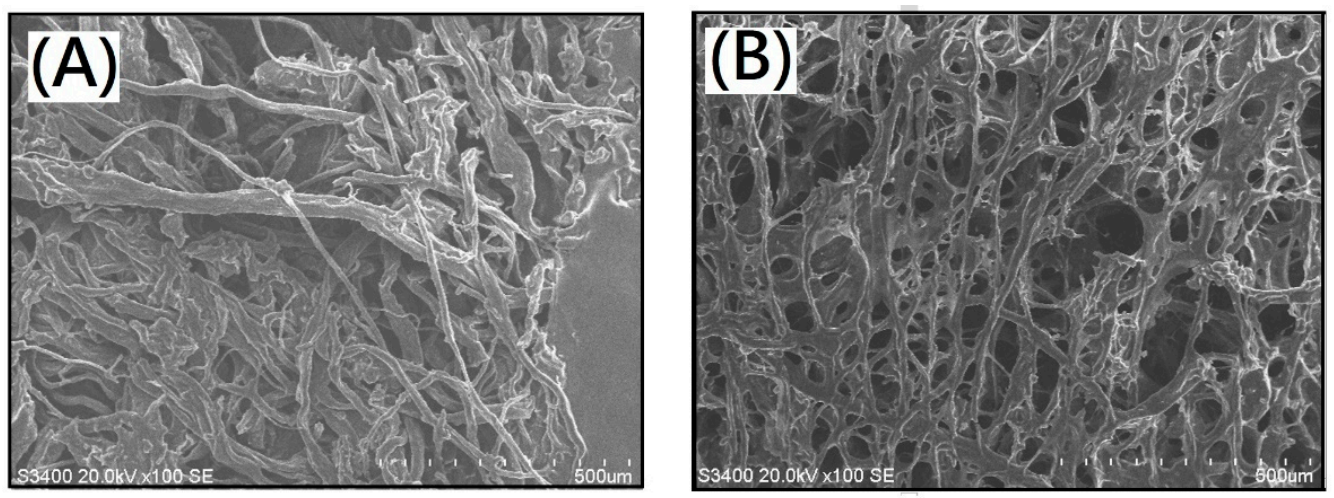

Figure 3. Macroscopic images of the composite scaffold membranes (A) AdE4N and (B) AdE4L.
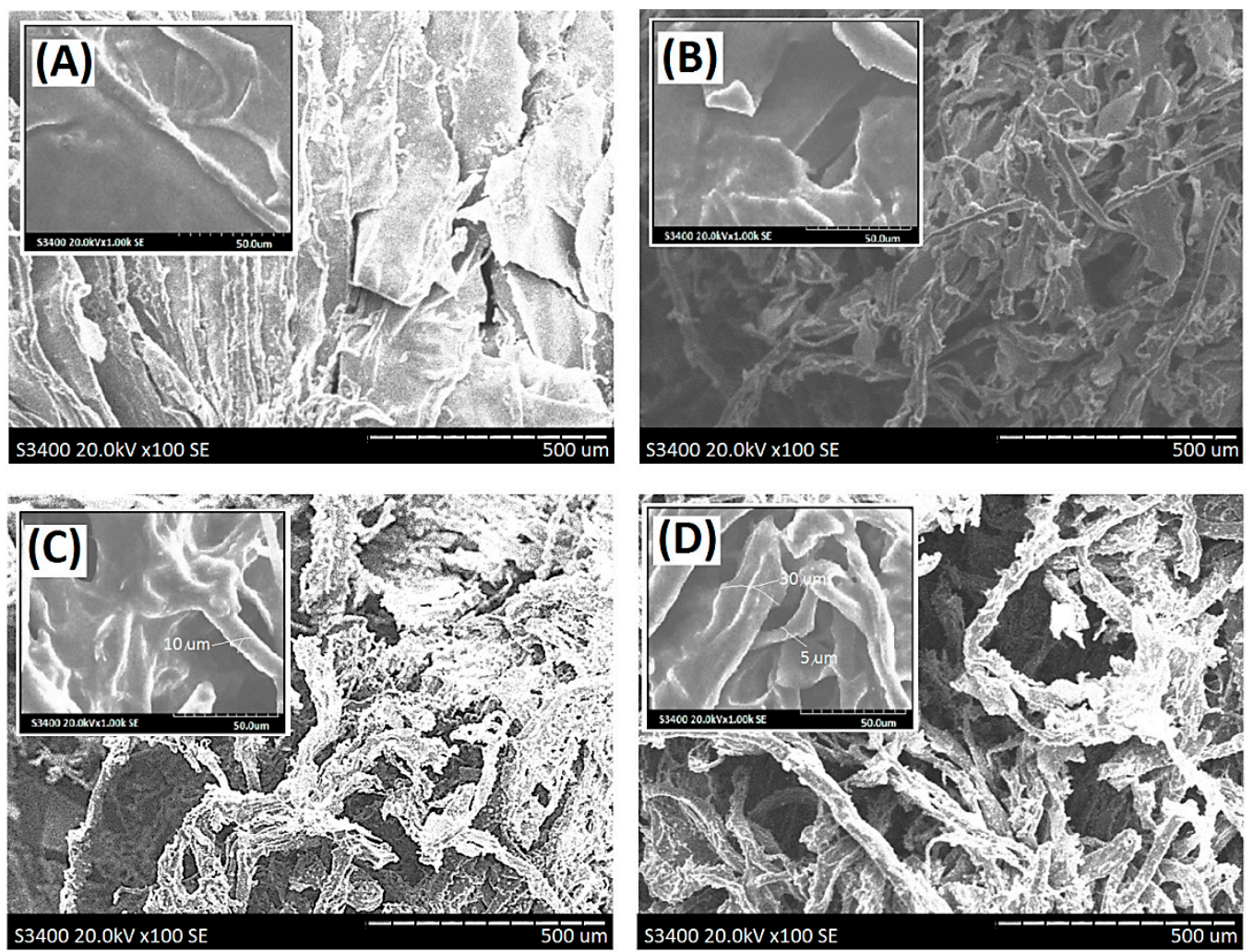

Figure 4. Scanning electron micrographs of the ALG/dECM composite scaffold membrane samples (A) AdE1H, (B) AdE2H, (C) AdE3H, and (D) AdE4H.

\subsection{Thermal Stability of Resulting Alginate/dECM Composite Scaffold Memebranes}

The thermal stability of resulting alginate/dECM composite scaffold membranes could be characterized by TGA. The peak temperatures of the derivative thermogravimetry (DTG) curves are summarized in Table 2. Due to the addition of each of the three components (Alginate $+\mathrm{dECM}+$ Calcium), there were three distinct peaks occurring and labelled as a, $\mathrm{b}$, and c (Table 2 and Figure 5). The maximum pyrolysis temperature $\left(\mathrm{T}_{\mathrm{d} \max }\right)$ of the original alginate material is lower than $250^{\circ} \mathrm{C}$. To enhance the thermal stability of the composite scaffold membranes, $\mathrm{dECM}$ was introduced. The $\mathrm{T}_{\mathrm{d} \max }$ of $\mathrm{dECM}$ is higher than $300^{\circ} \mathrm{C}$. The resulting composite scaffold membranes with dECM molecules would be designed as a new heat-resistant biomaterial. TGA analyses of ALG membranes with and without $\mathrm{CaCl}_{2}$ (AdE0N, AdE0H, AdE0L) were determined. The main loss was presented in three different temperature ranges, given by I $\left(<200{ }^{\circ} \mathrm{C}\right)$, II $\left(200-370^{\circ} \mathrm{C}\right)$ and $\mathrm{III}\left(370-500{ }^{\circ} \mathrm{C}\right)$. Initial weight loss up to $200{ }^{\circ} \mathrm{C}$ was found to be $15 \%, 18 \%$, and $20 \%$ for AdE0N, AdE0H, and AdEOL, respectively, due to the elimination of absorbed and bounded water molecules 
within the membrane. This increase in weight loss may be due to more adsorption of water molecules present along with $\mathrm{Ca}^{2+}$ molecules while cross-linking with $\mathrm{CaCl}_{2}$ aqueous solution. However, more interestingly, we observed that for the dECM loaded ALG/dECM membrane samples, the weight loss was less than $10 \%$. Furthermore, the second stage (stage II) of weight loss was observed from 200 to $370{ }^{\circ} \mathrm{C}$ and corresponds to thermal degradation of ECM molecules due to the breakage of the protein chains. The relatively high $\mathrm{T}_{\mathrm{dmax}}(\mathrm{b})$ values of $\mathrm{ALG} / \mathrm{dECM}$ were observed over $350{ }^{\circ} \mathrm{C}$ compared to $330{ }^{\circ} \mathrm{C}$ for the $\mathrm{dECM}$ molecule. Additionally, the relatively high $\mathrm{T}_{\mathrm{dmax}}(\mathrm{a})$ values of non-cross-linked ALG/dECM composite scaffold membranes (such as AdE1N, AdE2N, AdE3N, and AdE4N) were observed to range from 260 to $300{ }^{\circ} \mathrm{C}$ compared to $245^{\circ} \mathrm{C}$ for the non-cross-linked ALG molecule (Table 2).

Table 2. TGA analysis of ALG/dECM composite scaffold membranes.

\begin{tabular}{|c|c|c|c|}
\hline Sample No. & a & $\mathbf{b}$ & c \\
\hline $\operatorname{AdE} 0 N^{(a)}$ & $245^{\circ} \mathrm{C}$ & $-(\mathrm{d})$ & $-(\mathrm{d})$ \\
\hline $\operatorname{AdE1N}^{(a)}$ & $260{ }^{\circ} \mathrm{C}(32 \mathrm{wt} \%)$ & $360{ }^{\circ} \mathrm{C}(11 w \mathrm{t} \%)$ & $-(\mathrm{d})$ \\
\hline $\operatorname{AdE}_{2}{ }^{(a)}$ & $260{ }^{\circ} \mathrm{C}\left(28 w t^{\circ} \%\right)$ & $360{ }^{\circ} \mathrm{C}(15 w t \%)$ & $-(\mathrm{d})$ \\
\hline $\operatorname{AdE} \mathrm{N}^{(\mathrm{a})}$ & $260{ }^{\circ} \mathrm{C}(10 w \mathrm{t} \%)$ & $360{ }^{\circ} \mathrm{C}(26 \mathrm{wt} \%)$ & $-(\mathrm{d})$ \\
\hline $\operatorname{AdE} 4 N^{(a)}$ & $260{ }^{\circ} \mathrm{C}(8 \mathrm{wt} \%)$ & $360{ }^{\circ} \mathrm{C}(27 \mathrm{wt} \%)$ & $-(\mathrm{d})$ \\
\hline $\mathrm{dE}^{(\mathrm{a})}$ & $-^{(\mathrm{d})}$ & 330 & $-(\mathrm{d})$ \\
\hline $\operatorname{AdE0L~}(a, b)$ & $260^{\circ} \mathrm{C}$ & $-(\mathrm{d})$ & $-(\mathrm{d})$ \\
\hline $\operatorname{AdE1L}^{(\mathrm{a}, \mathrm{b})}$ & $265^{\circ} \mathrm{C}\left(20 w t^{\circ} \%\right)$ & $350{ }^{\circ} \mathrm{C}\left(35 w \mathrm{t}^{\circ} \%\right)$ & $-(\mathrm{d})$ \\
\hline AdE2L (a,b) & $268^{\circ} \mathrm{C}\left(15 w \mathrm{t}^{\circ} \%\right)$ & $360^{\circ} \mathrm{C}(23 w \mathrm{t} \%)$ & $410^{\circ} \mathrm{C}(17 \mathrm{wt} \%)$ \\
\hline $\operatorname{AdE3L~}^{(a, b)}$ & $280{ }^{\circ} \mathrm{C}(12 \mathrm{wt} \%)$ & $360{ }^{\circ} \mathrm{C}(24 w \mathrm{t} \%)$ & $410^{\circ} \mathrm{C}\left(19 w t^{\circ} \%\right)$ \\
\hline $\operatorname{AdE4L~}(a, b)$ & $285^{\circ} \mathrm{C}(5 \mathrm{wt} \%)$ & $370{ }^{\circ} \mathrm{C}(25 \mathrm{wt} \%)$ & $410^{\circ} \mathrm{C}(25 \mathrm{wt} \%)$ \\
\hline $\operatorname{AdE} 0 H^{(a, c)}$ & $280^{\circ} \mathrm{C}$ & $-(\mathrm{d})$ & $-(\mathrm{d})$ \\
\hline $\operatorname{AdE} 1 H^{(a, c)}$ & $298^{\circ} \mathrm{C}(15 w \mathrm{t} \%)$ & $-(\mathrm{d})$ & $390^{\circ} \mathrm{C}(20 w t \%)$ \\
\hline $\operatorname{AdE} 2 H^{(a, c)}$ & $298^{\circ} \mathrm{C}(9 \mathrm{wt} \%)$ & $360^{\circ} \mathrm{C}(18 w \mathrm{t} \%)$ & $410^{\circ} \mathrm{C}(22 \mathrm{wt} \%)$ \\
\hline $\operatorname{AdE} 3 \mathrm{H}^{(\mathrm{a}, \mathrm{c})}$ & $298^{\circ} \mathrm{C}(6 \mathrm{wt} \%)$ & $360{ }^{\circ} \mathrm{C}(18 w \mathrm{t} \%)$ & $410^{\circ} \mathrm{C}(27 \mathrm{wt} \%)$ \\
\hline $\operatorname{AdE} 4 \mathrm{H}^{(\mathrm{a}, \mathrm{c})}$ & $300{ }^{\circ} \mathrm{C}(5 \mathrm{wt} \%)$ & $385^{\circ} \mathrm{C}(18 w \mathrm{t} \%)$ & $420^{\circ} \mathrm{C}(30 \mathrm{wt} \%)$ \\
\hline
\end{tabular}

(a) $\mathrm{ALG}(\mathrm{A})$ : alginate and $\mathrm{dECM}(\mathrm{dE})$ : Porcine skins via $\mathrm{ScCO}_{2}$ and papain treatments; ${ }^{(\mathrm{b})} 1.0 \mathrm{wt} \% \mathrm{CaCl}_{2(\mathrm{aq})}$; (c) $5.0 \mathrm{wt} \% \mathrm{CaCl}_{2}(\mathrm{aq}) ;$ (d) No peak in DTG curve.

When $\mathrm{CaCl}_{2}(5 \mathrm{wt} \%)$ was added into the low dECM-loaded ALG/dECM membrane samples, the relatively high $\mathrm{T}_{\mathrm{dmax}}(\mathrm{a})$ of the cross-linked ALG molecule in AdE1H was observed at $298^{\circ} \mathrm{C}$ compared to $245^{\circ} \mathrm{C}$ for the non-cross-linked ALG molecule in AdE1N and $270^{\circ} \mathrm{C}$ for the slight cross-linked ALG molecule in AdE1L (Figure 5A-C). This was due to the cross-linking reaction among $\mathrm{CaCl}_{2}$ and multiple ALG molecules. A new $\mathrm{T}_{\mathrm{dmax}}(\mathrm{c})$ was observed at $390^{\circ} \mathrm{C}$ in Figure 5C, which might be due to the cross-linking reaction among $\mathrm{CaCl}_{2}$ and multiple dECM molecules. Similarly, a relatively high $\mathrm{T}_{\mathrm{dmax}}(\mathrm{a})$ was observed in a high dECM-loaded AdE4H with a high addition of $\mathrm{CaCl}_{2}(5 \mathrm{wt} \%)$ compared to AdE4N $\left(260^{\circ} \mathrm{C}\right)$ and AdE4L $\left(285^{\circ} \mathrm{C}\right)$ (Figure 5D-F and Table 2). Particularly, a high $\mathrm{T}_{\mathrm{dmax}}(\mathrm{c})$ at $420^{\circ} \mathrm{C}$ was observed on the DTG curve of AdE4H (Figure 5F), which might be due to the composite associations and cross-linking reaction among $\mathrm{CaCl}_{2}$, multiple ALG molecules, and multiple dECM molecules. New mixed cross-linked network microstructures of ALG molecules and AECM molecules might be formed.

When a small amount of dECM was introduced into the ALG/dECM composite scaffold membrane without $\mathrm{CaCl}_{2}$, a weak ionic association between - $\mathrm{COOH}$ groups of ALG molecules and $-\mathrm{NH}_{2}$ groups of dECM molecules was formed. Therefore, it was difficult to build up the cross-linking structure. With an increasing addition of dECM to ALG/dECM composite scaffold membranes, the ordinary ionic association between $-\mathrm{COOH}$ groups of ALG molecules and $-\mathrm{NH}_{2}$ groups of dECM molecules was employed to build a weak ionic cross-linking microstructure. When a large amount of $\mathrm{dECM}$ was introduced into the ALG/dECM composite scaffold membrane without $\mathrm{CaCl}_{2}$, a strong ionic association between - $\mathrm{COOH}$ groups of ALG molecules and $-\mathrm{NH}_{2}$ groups of dECM 
molecules was employed to build up the strong ionic cross-linking microstructure. The addition of $\mathrm{CaCl}_{2}$ induced various ionic associations among - $\mathrm{COOH}$ groups of ALG molecules, $-\mathrm{COOH}$ groups of $\mathrm{dECM}$ molecules, and $\mathrm{Ca}^{2+}$ ions. The remarkably high $\mathrm{T}_{\mathrm{dmax}}$ (c) was observed to be over $400{ }^{\circ} \mathrm{C}$ (Table 2). It is important to mention that most of the weight loss occurred at temperatures above human body temperature, which indicates that all these structures will be very stable under bodily conditions. This certainly showed that the introduction and cross-linking of $\mathrm{dECM}$ and alginate increased resistance to pyrolysis and provided stability to the composite scaffold membranes that could be considered to be a suitable potential material for soft tissue implants and bioprinting applications [21].

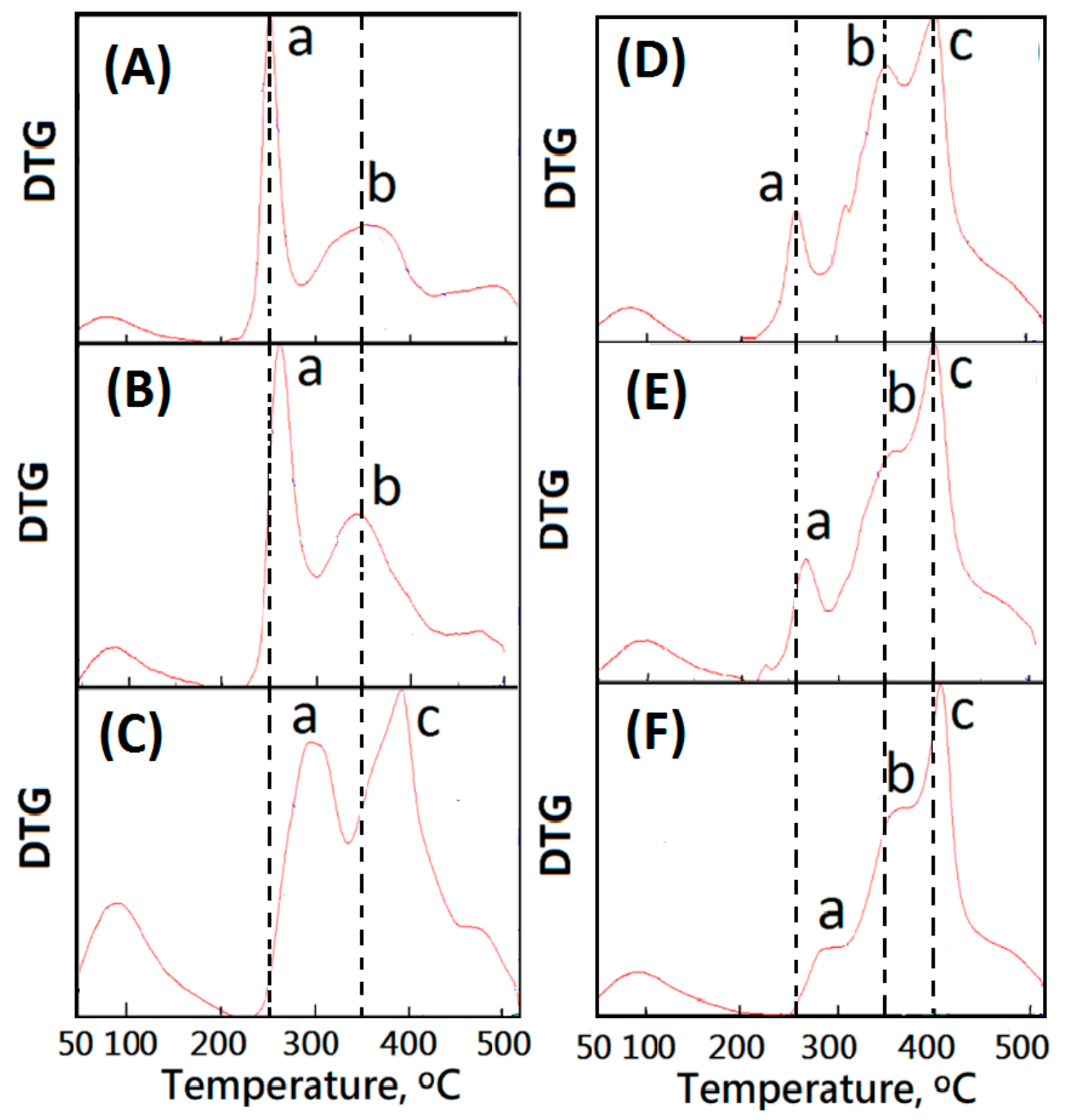

Figure 5. DTG curves of the composite scaffold membranes cross-linked with various concentrations of $\mathrm{CaCl}_{2(\mathrm{aq})}$ : (A) $\operatorname{AdE} 1 \mathrm{~N}(0 \mathrm{wt} \%),(\mathbf{B}) \operatorname{AdE} 1 \mathrm{~L}(1 \mathrm{wt} \%),(\mathbf{C}) \operatorname{AdE} 1 \mathrm{H}(5 \mathrm{wt} \%),(\mathbf{D}) \operatorname{AdE} 4 \mathrm{~N}(0 \mathrm{wt} \%)$, (E) $\operatorname{AdE} 4 \mathrm{~L}(1 \mathrm{wt} \%)$, and (F) $\operatorname{AdE} 4 \mathrm{H}(5 \mathrm{wt} \%)$.

\section{Conclusions}

In this study, new composite scaffold membranes with collagen scaffolds were successfully obtained from alginate and AECM that was prepared from porcine skin using supercritical carbon dioxide fluid technology. The retained extracellular matrix and integrity scaffold structures were observed. This work provides a simple and time-saving method to process decellularized tissue. The network-scaffold microstructures were observed in new composite scaffold membranes with collagen scaffolds. Composite scaffold membranes with high thermal stability were obtained, which indicates that these membranes will be very stable under bodily conditions. The resulting composite scaffold 
membranes with fibrous micro-scaffold structures could be considered to be a potential material for bioprinting applications.

Funding: This research received no external funding.

Institutional Review Board Statement: Not applicable.

Informed Consent Statement: Not applicable.

Data Availability Statement: Data available on request due to restrictions eg privacy or ethical.

Conflicts of Interest: The authors declare no conflict of interest.

\section{References}

1. Malda, J. 25th anniversary article: Engineering hydrogels for biofabrication. Adv. Mater. 2013, 25, 5011-5028. [CrossRef]

2. Jiang, T.; Munguia-Lopez, J.G.; Flores-Torres, S.; Grant, J.; Vijayakumar, S.; Leon-Rodriguez, A.D.; Kinsella, J.M. Directing the self-assembly of tumor spheroids by bioprinting cellular heterogeneous models within Alginate/Gelatin hydrogels. Sci. Rep. 2017, 7, 4575. [CrossRef]

3. Benwood, C.; Chrenek, J.; Kirsch, R.L.; Masri, N.Z.; Richards, H.; Teetzen, K.; Willerth, S.M. Natural Biomaterials and Their Use as Bioinks for Printing Tissues. Bioengineering 2021, 8, 27. [CrossRef]

4. Sherifi, I.; Bachy, M.; Laumonier, T. Use of supercritical carbon dioxide technology for fabricating a tissue engineering scaffold for anterior cruciate ligament repair. Sci. Rep. 2020, 10, 14030. [CrossRef] [PubMed]

5. Yu, C.; Ma, X.; Zhu, W.; Wang, P.; Miller, K.L.; Stupin, J.; Koroleva-Maharajh, A.; Hairabedian, A.; Chen, S. Scanningless and continuous 3D bioprinting of human tissues with decellularized extracellular matrix. Biomaterials 2019, 194, 1-13. [CrossRef] [PubMed]

6. Liu, Y.W.; Huang, C.C.; Wang, Y.Y.; Xu, J.; Wang, G.D.; Bai, X.P. Biological evaluations of decellularized extracellular matrix collagen microparticles prepared based on plant enzymes and aqueous two-phase method. Regen. Biomater. 2021, 8, rbab002. [CrossRef] [PubMed]

7. Zhai, G.; Toh, S.C.; Tan, W.L.; Kang, E.T.; Neoh, K.G.; Huang, C.C.; Liaw, D.J. Poly(vinylidene fluoride) with Grafted Zwitterionic Polymer Side Chains for Electrolyte-Responsive Microfiltration Membranes. Langmuir 2003, 19, 7030-7037. [CrossRef]

8. Vanaei, S.; Parizi, M.S.; Vanaei, S.; Salemizadehparizi, F.; Vanaei, H.R. An Overview on Materials and Techniques in 3D Bioprinting Toward Biomedical Application. Eng. Regen. 2021, 2, 1-18.

9. Shin, Y.J.; Shafranek, R.T.; Tsui, J.H.; Walcott, J.; Nelson, A.; Kim, D.H. 3D bioprinting of mechanically tuned bioinks derived from cardiac decellularized extracellular matrix. Acta Biomater. 2021, 119, 75-88. [CrossRef] [PubMed]

10. Mandrycky, C.; Wang, Z.; Kim, K.; Kim, D.H. 3D bioprinting for engineering complex tissues. Biotechnol. Adv. 2016, 34, 422-423. [CrossRef] [PubMed]

11. Kabirian, F.; Mozafari, M. Decellularized ECM-derived bioinks: Prospects for the future. Methods 2020, 171, 108-118. [CrossRef]

12. Smidsrød, O.; Skjak-Braek, G. Alginate as immobilization matrix for cells. Trends Biotechnol. 1990, 8, 71-78. [CrossRef]

13. Lee, K.Y.; Mooney, D.J. Alginate: Properties and biomedical applications. Prog. Polym. Sci. 2012, 37, 106-126. [CrossRef]

14. Anal, A.K.; Stevens, W.F. Chitosan-alginate multilayer beads for controlled release of ampicillin. Int. J. Pharm. 2005, 290, 45-54. [CrossRef] [PubMed]

15. Baldwin, A.D.; Kiick, K.L. Polysaccharide-modified synthetic polymeric biomaterials. Biopolymers 2010, 94, 128-140. [CrossRef] [PubMed]

16. Zhang, H.; Cheng, J.; Ao, Q. Preparation of Alginate-Based Biomaterials and Their Applications in Biomedicine. Mar. Drugs 2021, 19, 264. [CrossRef] [PubMed]

17. Piras, C.C.; Smith, D.K. Multicomponent polysaccharide alginate-based bioinks. J. Mater. Chem. B 2020, 8, 8171-8188. [CrossRef] [PubMed]

18. Ma, X.; Yu, C.; Wang, P.; Xu, W.; Wan, X.; Sun, C.; Lai, E.; Liu, J.; Koroleva-Maharajh, A.; Chen, S. Rapid 3D bioprinting of decellularized extracellular matrix with regionally varied mechanical properties and biomimetic microarchitecture. Biomaterials 2018, 185, 310-321. [CrossRef] [PubMed]

19. Vogel, K.G.; Trotter, J.A. The Effect of Proteoglycans on the Morphology of Collagen Fibrils Formed In Vitro. Collagen Relat. Res. 1987, 7, 105-114. [CrossRef]

20. Curley, C.J.; Dolan, E.B.; Otten, M. An injectable alginate/extra cellular matrix (ECM) hydrogel towards acellular treatment of heart failure. Drug Deliv. Transl. Res. 2019, 9, 1-13. [CrossRef] [PubMed]

21. Valencia, C.; Valencia, C.H.; Zuluaga, F.; Valencia, M.E.; Mina, J.H.; Grande-Tovar, C.D. Synthesis and Application of Scaffolds of Chitosan-Graphene Oxide by the Freeze-Drying Method for Tissue Regeneration. Molecules 2018, 23, 2651. [CrossRef] [PubMed] 